\title{
MULTI-TEMPORAL MONITORING OF URBAN RIVER WATER QUALITY USING UAV-BORNE MULTI-SPECTRAL REMOTE SENSING
}

\author{
Chun Liu ${ }^{1}$, Xiaoteng Zhou ${ }^{1,}$ *, Yuan Zhou ${ }^{2}$, Akram Akbar ${ }^{1}$ \\ ${ }^{1}$ College of Surveying and Geo-informatics, Tongji University, Shanghai 200092, China \\ liuchun@tongji.edu.cn, 729zxt@tongji.edu.cn, akram@tongji.edu.cn \\ ${ }^{2}$ Tongfang Surveying Engineering and Technology Co. Ltd., Shanghai 201900, China \\ zhouyuan@tongfantech.com
}

KEY WORDS: Multi-Spectral Remote Sensing, Water Quality Monitoring, UAV, Multi-Temporal, Urban River

\begin{abstract}
:
Water quality is an important index of the ecological environment, which changes rapidly and needs to be monitored chronically. In urban ecological environment, water quality problem is not only more serious, but also more complex in time and space. Remote sensing water quality monitoring can cover a large area in a short time. Therefore, remote sensing can be adopted to make up for the shortcomings of traditional water quality monitoring methods in space coverage and temporal resolution. In order to monitor the narrow rivers in urban area, low altitude remote sensing is needed. This paper proposes a multi-spectral water quality monitoring method based on UAV platform, which can quickly monitor an entire urban water area and conduct multi-temporal observation for key indices of water quality within one day. It is helpful to find and locate the polluted areas which affect the water environment quickly. Also, it can show the changes of water quality on the time axis. The result can provide a decision-making basis for water environment treatment.
\end{abstract}

\section{INTRODUCTION}

Water quality of the urban river directly affects the ecological environment quality. However, due to the time and space uncertainty of rain and wastewater discharge, water quality of the river changes frequently. Therefore, it is necessary to monitor the whole water area with high accuracy and multi-temporal, and to obtain the water quality of rivers in time. The traditional methods of urban river water quality monitoring are to use high-precision manual sampling or set up monitoring stations (Behmel et al., 2016). But the efficiency of manual sampling is low. Monitoring station cost is extremely high. Moreover, monitoring the water quality trend of the whole river is a big challenge for water quality monitoring.

Multi-spectral remote sensing technology can monitor water quality in a large area rapidly. At present, there has been a large number of researches on remote sensing water quality monitoring (Gholizadeh et al., 2016). They have developed from qualitative monitoring to quantitative monitoring, and have achieved certain results. A large number of these studies are focused on case 1 waters and case 2 waters such as seas, large rivers and lakes (Wang, Yang, 2019). When it comes to the urban river, more efficient and higher resolution methods are needed due to the frequent changes in water quality (Vidon et al., 2008) and narrow river width. Also, specific water quality indices need corresponding sensitive bands to monitor because of the complex factors which affect the urban water environment (Liu et al., 2016).

Unmanned aerial vehicle (UAV) remote sensing has the characteristics of flexibility, efficiency and high resolution (Stöcker et al., 2017), which is an effective solution for the multitemporal monitoring of urban river water quality. This paper proposed a UAV-borne multi-spectral remote sensing method for multi-temporal monitoring of urban river water quality. Water quality monitoring process of an entire urban river can be shortened within one day. In this method, narrowband multispectral array camera is used for monitoring to improve the observation precision which can freely customize the bands for specific water quality indices. Based on the orthophoto map and image registration, the river area is clipped, which can save time from establishing orthophoto map and increase the efficiency. Aiming at the problem of solar radiance changes on the ground, collecting data from the sky and the ground synchronously is carried out to ensure the accuracy of the image correction and the river reflectance calculation. Support Vector Machine (SVM) is used to classify the water quality.

\section{METHODOLOGY}

\subsection{Reflectance Calculation and Band Selection for Water Quality Monitoring}

The data set of water quality indices and spectrum is constructed, in order to prepare for the band selection. The water samples and spectral data of urban rivers are collected simultaneously.

Above-water measurement (Fargion, Mueller, 2000; Lee et al., 1997 ) is used to collect spectrum. The water leaving radiance $L_{w}$ above the water surface does not change much in the range of zenith angle $0^{\circ} \sim 40^{\circ}$. The angle between observation plane of the spectrometer and incident plane of the sun is $90^{\circ} \leqslant \varphi v \leqslant 135^{\circ}$, in order to avoid the damage of the light field caused by the specular reflection of the sun and the shadow of surrounding objects. The angle between the spectrometer and normal line of the water surface is $30^{\circ} \leqslant \theta_{v} \leqslant 45^{\circ}$. In this way, most of the specular reflection of the sun can be avoided, and the shadow effect of the surrounding objects can be reduced. The purpose of spectral information preprocessing is to obtain the normalized reflectance of the whole band. The following is the specific process.

* Corresponding author 
A. water leaving radiance calculation

$$
\mathrm{L}_{\mathrm{w}}=\mathrm{L}_{\mathrm{sw}}-\mathrm{r} * \mathrm{~L}_{\mathrm{sky}}
$$

Where, $\mathrm{L}_{\mathrm{W}}$ is the water leaving radiance. $\mathrm{L}_{\mathrm{sW}}$ is the total radiance signal received by the spectrometer. $L_{s k y}$ is the sky diffusion light. $\mathrm{r}$ is the Fresnel reflection coefficient of the air-water interface to the sky light, which is generally 0.028 .

B. water surface incident irradiance calculation

$$
\mathrm{E}_{\mathrm{d}}\left(0^{+}\right)=\mathrm{L}_{\mathrm{p}} * \pi / \rho_{\mathrm{p}}
$$

Where, $\mathrm{E}_{\mathrm{d}}\left(0^{+}\right)$is the water surface incident irradiance. $\mathrm{L}_{\mathrm{p}}$ is the radiance measured from standard reflecting board. $\rho_{p}$ is the reflectance of standard reflecting board. Before measurement, the standard reflecting board should be strictly calibrated. In this paper, a white standard reflecting board is used, the reflectance of which is $99 \%$.

C. reflectance calculation

According to formula (1) and formula (2), the calculation formula of reflectance Rrs can be obtained as follow.

$$
\operatorname{Rrs}=\frac{\mathrm{Lw}}{\mathrm{E}_{\mathrm{d}}\left(0^{+}\right)}=\frac{\mathrm{L}_{\mathrm{sw}}-\mathrm{r}^{*} \mathrm{~L}_{\text {sky }}}{\mathrm{L}_{\mathrm{p}}{ }^{*} \pi / \rho_{\mathrm{p}}}
$$

D. normalized reflectance calculation

Due to the influence of weather, background and measurement angle, the reflectance may change. It is necessary to normalize the reflectance of all bands. The calculation formula of normalized reflectance $\mathrm{Rrs}^{\prime}$ can be obtained as follow.

$$
\operatorname{Rrs}_{i}{ }^{\prime}=\frac{\operatorname{Rrs}_{\mathrm{i}}}{\sqrt{\sum_{\mathbf{i}=1}^{\mathrm{N}} \operatorname{Rrs}_{\mathrm{i}}^{2}}}
$$

Where, $\mathrm{N}$ is the number of the bands. $\mathrm{i}$ is one of the bands.

The water quality indices which need to be monitored are analyzed in the laboratory. This laboratory has passed the China Metrology Accreditation (CMA). The samples of different water quality situations are collected, which are representative.

By analyzing the correlation between spectral data and water quality indices and the information entropy, the bands mounted on the multi-spectral camera are selected. K-means clustering algorithm is used to eliminate the abnormal data. Correlation coefficient between the normalized reflectance and the concentration of water quality indices is calculated. The correlation coefficient formula is as follow, and the correlation coefficient curve can be obtained.

$$
\mathrm{R}\left(\operatorname{Rrs}^{\prime}, \mathrm{I}\right)=\frac{\operatorname{Cov}\left(\operatorname{Rrs}^{\prime}, \mathrm{I}\right)}{\sqrt{\operatorname{Var}\left[\operatorname{Rrs}^{\prime}\right] \operatorname{Var}[1]}}
$$

Where, I is the concentration of water quality indices. $\operatorname{Cov}\left(\operatorname{Rrs}^{\prime}, \mathrm{I}\right)$ is the covariance between $\operatorname{Rrs}^{\prime}$ and I. Var[Rrs'] is the variance of Rrs', and $\operatorname{Var}[\mathrm{I}]$ is the variance of $\mathrm{I}$.

The information entropies of each band are calculated. The formula of information entropy is as follow.

$$
\mathrm{H}(\text { band })=-\sum_{\mathrm{i}=1}^{\mathrm{n}} \mathrm{p}\left(\operatorname{Rrs}_{\mathrm{i}}{ }_{\mathrm{i}}\right) \log \left(\mathrm{p}\left(\operatorname{Rrs}_{\mathrm{i}}{ }_{\mathrm{i}}\right)\right)
$$

Where, $\mathrm{H}$ (band) represents the information entropy of a certain band, $p\left(\operatorname{Rrs}^{\prime}{ }_{i}\right)$ represents the occurrence probability of a certain band reflectance value $\operatorname{Rrs}^{\prime}{ }_{i}$. The larger information entropy is, the more abundant information is contained in the band.
Considering the correlation coefficient and information entropy, the band with larger correlation coefficient and information entropy is selected as the mount band of multispectral camera. Also, considering the performance parameters of camera, the band width is determined to ensure imaging quality.

\subsection{Remote Sensing Data Collection and Image Correction}

Orthophoto map of the monitoring area is established which is used as the base map for remote sensing image registration. The vector map of the river area is extracted from the base map. In this way, time can be saved from establishing the orthophoto map and increase the efficiency.

The patrol route is used in multi-spectral images acquisition to take the place of traditional photogrammetry route, which can reduce data quantity and data acquisition time (Cabreira et al., 2019). UAV flies along the river centerline. Set the images to overlap three times to ensure redundant observation. In order to improve the signal-noise ratio of the image and avoid the specular reflection of the river water, the solar elevation angle shall be between $35^{\circ}$ and $65^{\circ}$ during the collection of the images (Wang, 2006).

At the same time of collecting the remote sensing image of the ground, solar radiance is collected simultaneously. Use a $99 \%$ standard reflector and spectrometer to collect the water entering radiance. Both the images and solar radiance data use the GPS (Global Positioning System) Timing System. The solar radiance curve can be obtained by cubic spline interpolation. This curve can be used as a reference for relative radiometric correction and ground surface reflectance calculation.

The images are corrected, according to the absolute radiometric calibration (Minarík et al., 2019) and geometric calibration (Nocerino et al., 2017) of the camera in advance. The general position of each image is determined on the base map according to the GPS information. SIFT (Scale-invariant feature transform) is used to match the corresponding points and then the points are checked manually. Registration is carried out by image space transformation to the base map. The vector map of river area is used to clip the river part from remote sensing images. Based on the solar radiance curve, the corrected image and formula (3), the river reflectance image is obtained. The process of remote sensing data collection and image correction is shown in Figure 1.

\subsection{Water Quality Classification Modeling}

The reflectance of the selected bands and water quality indices data are set to be the training data. Based on the training data, SVM water quality classification model is established. The concentration of each water quality index is divided into six classes according to the National Standard of the People's Republic of China "Environmental quality standards for surface water" (GB3838-2002). The six classes are Class I, Class II, Class III, Class IV, Class V and Worse than Class V. Class I is the best water quality and Worse than Class $\mathrm{V}$ is the worst.

Using the reflectance of each selected band as the $\mathrm{n}$-dimensional vector of the training set. The labels are divided into six classes according to the six water quality classes. Optimal kernel function, slack variable, penalty parameter and gamma coefficient are selected to construct a hyperplane. The penalty parameter follows the classification optimization problems below: 


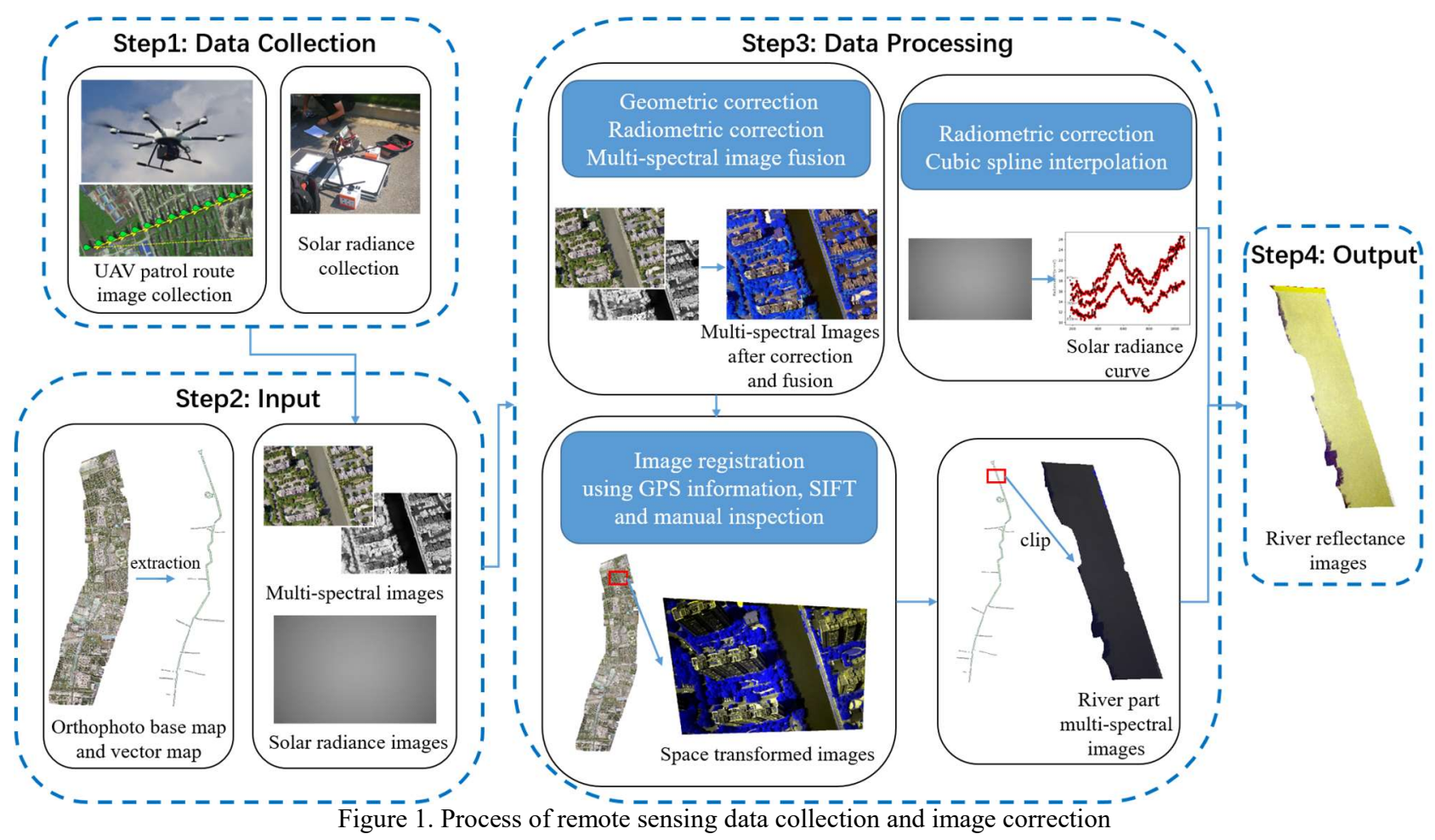

$$
\begin{gathered}
\min \frac{1}{2}\|w\|+C \sum_{i=1}^{\mathrm{i}} \xi_{\mathrm{i}} \\
\text { s.t. } \mathrm{y}_{\mathrm{i}}\left[\left(w \mathrm{w}_{\mathrm{i}}\right)+\mathrm{b}\right] \geq 1-\xi_{\mathrm{i}}(\mathrm{i}=1,2, \ldots \ldots, \mathrm{n})\left(\xi_{\mathrm{i}} \geq 0\right)
\end{gathered}
$$

Where, $w$ is the coefficients of hyperplane equation. $\xi$ is the slack variable, which is the allowed amount of deviation from functional margin for corresponding training data points. $\mathrm{C}$ is the penalty parameter. The larger $\mathrm{C}$ is, the more strict classification is. But it is easy to be over-fitting, and the generalization ability is poor. On the contrary, the smaller $\mathrm{C}$ is, the easier it is to be under-fitting. When using kernel functions of 'RBF', 'poly' and 'sigmoid', the gamma coefficient needs to be optimized. The formula of gamma coefficient is as follows:

$$
\text { gamma }=\frac{1}{2 * \sigma^{2}}
$$

Where, $\sigma$ is the standard deviation parameter in the normal distribution. If gamma is larger, it is easier to be over-fitting, and has poor generalization ability. Conversely, the smaller gamma is, the easier it is to be under-fitting. In addition, SVM one-vsrest strategy is used to classify six classes. When the sample number in each class of water quality index is unbalanced, the balanced class weight method is used for training.

Finally, the water quality classification is carried out according to the SVM water quality classification model. The water quality classification result map is obtained.

\section{EXPERIMENT AND RESULTS}

\subsection{In-Situ Data Collection and Analysis}

The water quality indices which are monitored in this paper are total phosphorus (TP), ammonia nitrogen $\left(\mathrm{NH}_{3}-\mathrm{N}\right)$ and chemical oxygen demand (COD). These indices are important factors of urban water environment pollution. A total of 186 samples were collected in Shanghai China. ASD Handheld 2 Pro was used to collect spectral data. The samples follow the principle of water quality diversity and are representative. The class distribution of each water quality index of the samples is shown in the Table 1 below.

\begin{tabular}{cccc}
\hline Water Quality Class & COD & $\mathrm{NH}_{3}-\mathrm{N}$ & $\mathrm{TP}$ \\
\hline Class I & $118^{*}$ & 10 & 5 \\
Class II & 39 & 28 & 13 \\
Class III & 20 & 63 \\
Class IV & 22 & 11 & 57 \\
Class V & 5 & 51 & 31 \\
Worse than Class V & 2 & 66 & 17 \\
\hline
\end{tabular}

* The Class I and Class II of COD is the same in National Standard of the People's Republic of China.

Table 1. Class distribution of each water quality index of the samples

After eliminating the abnormal data and unstable bands caused by the atmospheric conditions, the correlation coefficients between the collected water spectrums and the quality index concentrations of water samples are analyzed. Also, the information entropy values of each band are calculated. The correlation coefficient curves and information entropy curve are shown in the Figure 2. It can be seen that the absolute value of the correlation coefficient is larger around $675 \mathrm{~nm}, 705 \mathrm{~nm}$ and $714 \mathrm{~nm}$. The information entropy is relatively large between $518 \mathrm{~nm}$ and $710 \mathrm{~nm}$. Therefore, considering the correlation coefficient and information entropy, $675 \mathrm{~nm}$ and $705 \mathrm{~nm}$ are selected. 


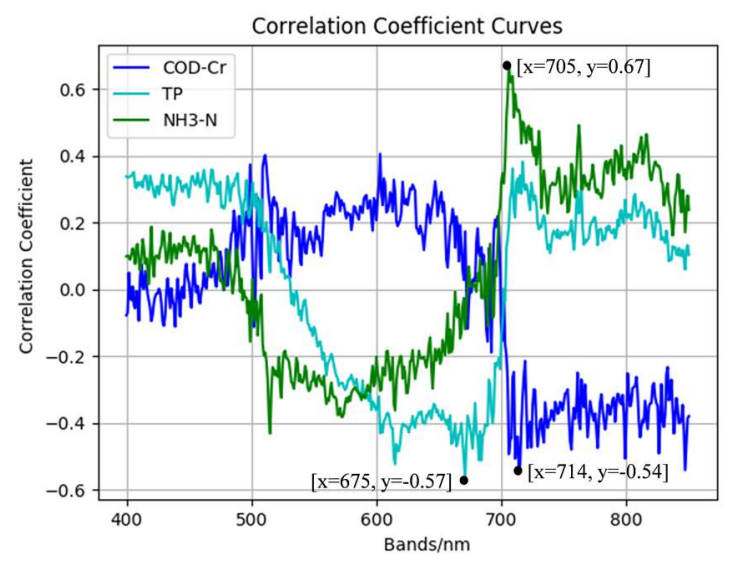

(a)

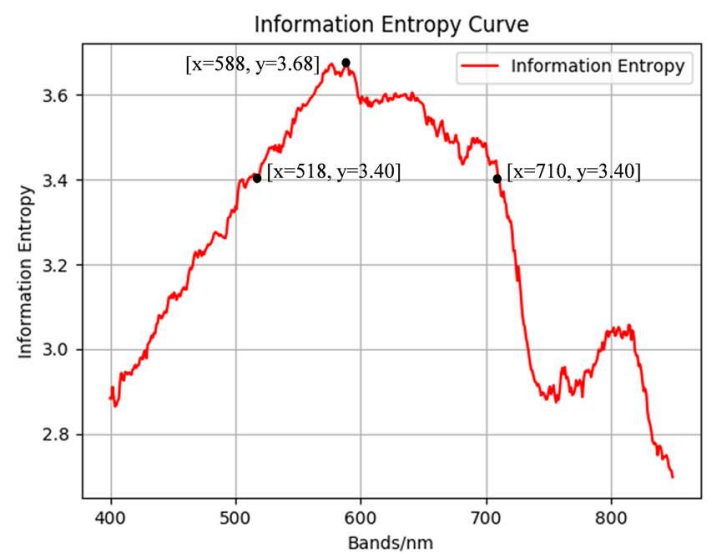

(b)

Figure 2. Correlation coefficient curves of water samples and spectrum information entropy curve

(a) Correlation coefficient curves (b) Information entropy curve

\subsection{Experiment Setting}

The experiment was performed on partial basin of the Taopu River in Shanghai, China. This river is an important tributary of the Shanghai urban area. The total length of the experimental basin is about $6 \mathrm{~km}$ and the width is about $30 \mathrm{~m}$.

A narrowband multi-spectral array camera was adopted to collect images. The picture frame of this camera is $6000 \times 4000$ pixels. The spatial resolution of $100 \mathrm{~m}$ altitude is $1.2 \mathrm{~cm}$ and the spectral resolution is $10 \mathrm{~nm}$. The bands it carries are RGB, $675 \mathrm{~nm}, 705 \mathrm{~nm}$ and $850 \mathrm{~nm}$ as near infrared supplement which is important band for water remote sensing (Ruddick et al., 2006).

Experiments were processed on May 7, May 22, July 4, and August 8, 2019. The altitude of the flight route was set as $300 \mathrm{~m}$ and each of the monitoring flights costs about 20min. The number of images acquired for each flight was about 200. The method proposed in this paper was used for water quality classification. It cost within one day to get the classification result

The checkpoints are evenly distributed in the study area. Water quality samples were taken as the checkpoints when the UAV was flying directly above. In May 7, July 4 and August 8 , a total of 25 checkpoints have been set up. The study site, flight path and distribution of checkpoints are shown in Figure 3 below.
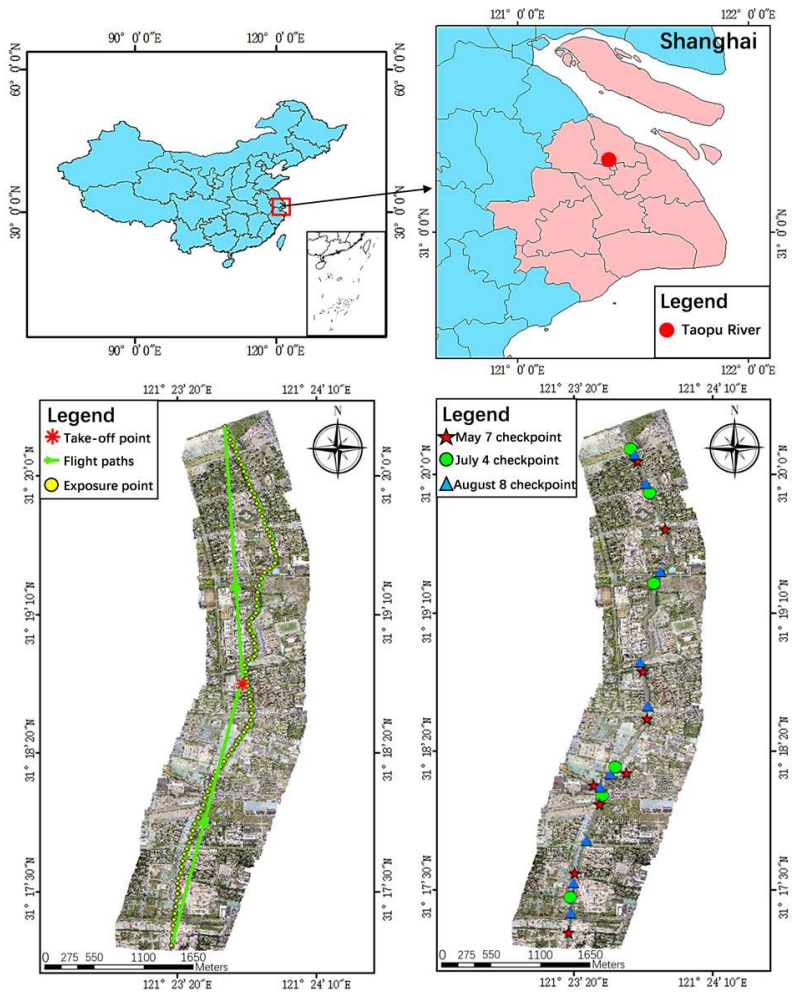

Figure 3. Study site, flight paths and checkpoints of Taopu River water quality monitoring

\subsection{Experiment Results}

SVM classification models are respectively trained for the three water quality indices. The training data are the reflectance of $675 \mathrm{~nm}, 705 \mathrm{~nm}$ and $850 \mathrm{~nm}$, and the labels are marked according to the six classes of water quality. The precision of the classification models are tested by the method of 5-fold crossvalidation. Confusion matrices and precision of the three water quality classification models are shown in the Table 2 and Figure 4.

\begin{tabular}{cccc}
\hline & $\mathrm{COD}$ & $\mathrm{NH}_{3}-\mathrm{N}$ & $\mathrm{TP}$ \\
\hline Average Precision & 0.86 & 0.74 & 0.76 \\
\hline
\end{tabular}

Table 2. Precision of the water quality SVM classification models

According to the six classes, classification results are represented by six colors which are shown in Figure 5 . From the results it can be seen that the situation of COD is between Class II and Class V. $\mathrm{NH}_{3}-\mathrm{N}$ is between Class $\mathrm{V}$ and Worse than Class V. TP is between Class II and Class V. Compared with the checkpoints, the classification precision of COD, $\mathrm{NH}_{3}-\mathrm{N}$ and $\mathrm{TP}$ are $72 \%, 96 \%$, and $76 \%$. The statistics of water quality classification precision are shown in Table 3.

\begin{tabular}{cccc}
\hline Classification Results & $\mathrm{COD}$ & $\mathrm{NH}_{3}-\mathrm{N}$ & $\mathrm{TP}$ \\
\hline Correct classification & 18 & 24 & 19 \\
Overestimate 1 class & 1 & 1 & 1 \\
Underestimate 1 class & 5 & 0 & 5 \\
Overestimate 2 classes & 1 & 0 & 0 \\
Classification precision & $72 \%$ & $96 \%$ & $76 \%$
\end{tabular}

Table 3. Statistics of water quality classification precision 


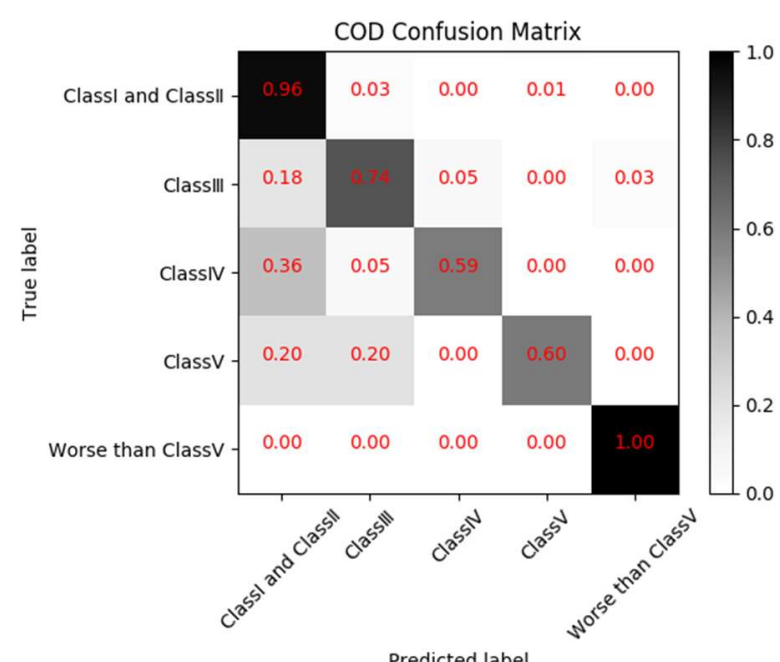

(a)

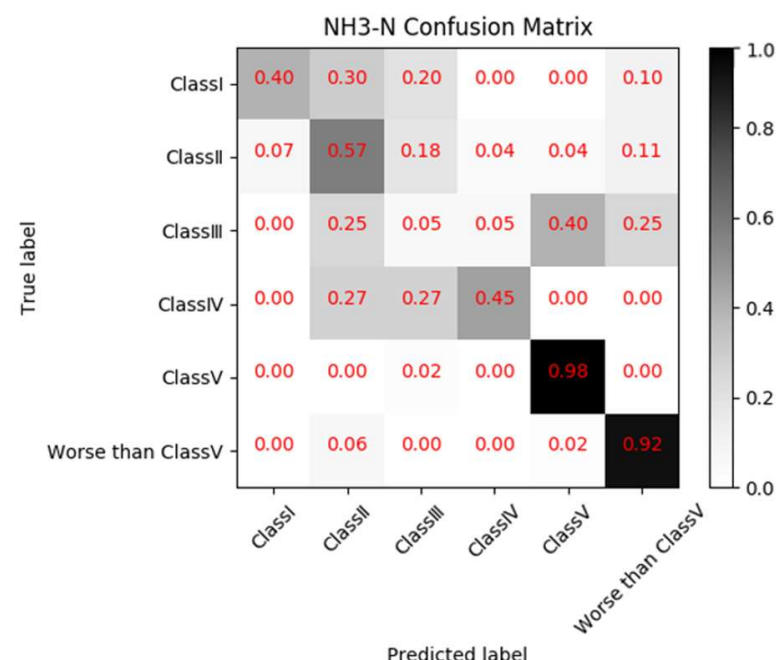

(b)

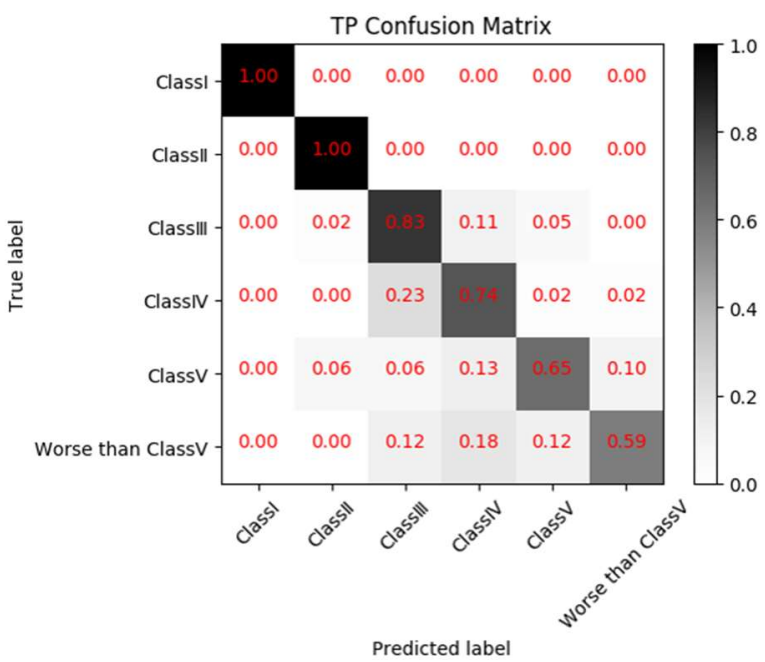

(c)

Figure 4. Confusion Matrices of water quality SVM classification models

(a) $\mathrm{COD}(\mathrm{b}) \mathrm{NH}_{3}-\mathrm{N}$ (c) $\mathrm{TP}$

\section{DISCUSSION AND CONCLUSION}

\subsection{Discussion}

From the result, it can be obviously seen that the water quality situation is not stable and is in constant change. Sometimes, the changes can be tremendous which needs multi-temporal observation. $\mathrm{COD}, \mathrm{NH}_{3}-\mathrm{N}$ and TP of Taopu River show different states on four days. Also, the water quality of the whole river basin is not the same. The water quality of the Taopu River is better in the middle part but poor at the north and south ends. The reason for this trend is that the river at both ends of the north and South are blocked. There are tributaries in the middle section, which can ensure the flow of river water. From the classification results of TP on May 22 and June 4, we can see some water quality catastrophe points. These points are suspected to be sewage outlets. According to the field investigation, sewage outlets do exist in these places.

Because the quality of ammonia nitrogen in Taopu River is stable between class $\mathrm{V}$ and worse than class $\mathrm{V}$, the precision of classification can reach $96 \%$. More experiments need to be carried out in more places to verify the practical application precision of the classification models. Chemical oxygen demand of the samples collected in Shanghai is mainly concentrated in Class I and class II, which reduces the generalization of the classification models. The number of sample needs to be expanded to balance the quantity of each water quality class.

\subsection{Conclusion}

The method proposed in this paper addresses the problems of frequent changes in the water quality of urban river and their spatial inconsistencies. UAV-borne multi-spectral remote sensing technology is used to achieve the purpose of multitemporal monitoring of surface water quality. While improving the monitoring efficiency, the precision of the classification results is guaranteed. The result can be a decision-making basis for water environment treatment. Basing on this method, improving the ability of recognition and increasing the bands can further broaden the scope of application. Furthermore, this method can be used as a reference for mission oriented UAVborne multi-spectral remote sensing applications.

\section{ACKNOWLEDGEMENTS}

This work was supported by National Key Research and Development Program of China (Grant No. 2018YFF0215304), National Key Research and Development Program of China (Grant No. 2018YFB1305000), General Program of National Natural Science Foundation of China (Grant No. 41771481), Innovation Action Plan of Science and Technology Commission of Shanghai Municipality (Grant No. 19DZ2200800) and the International Exchange Program for Graduate Students, Tongji University. 

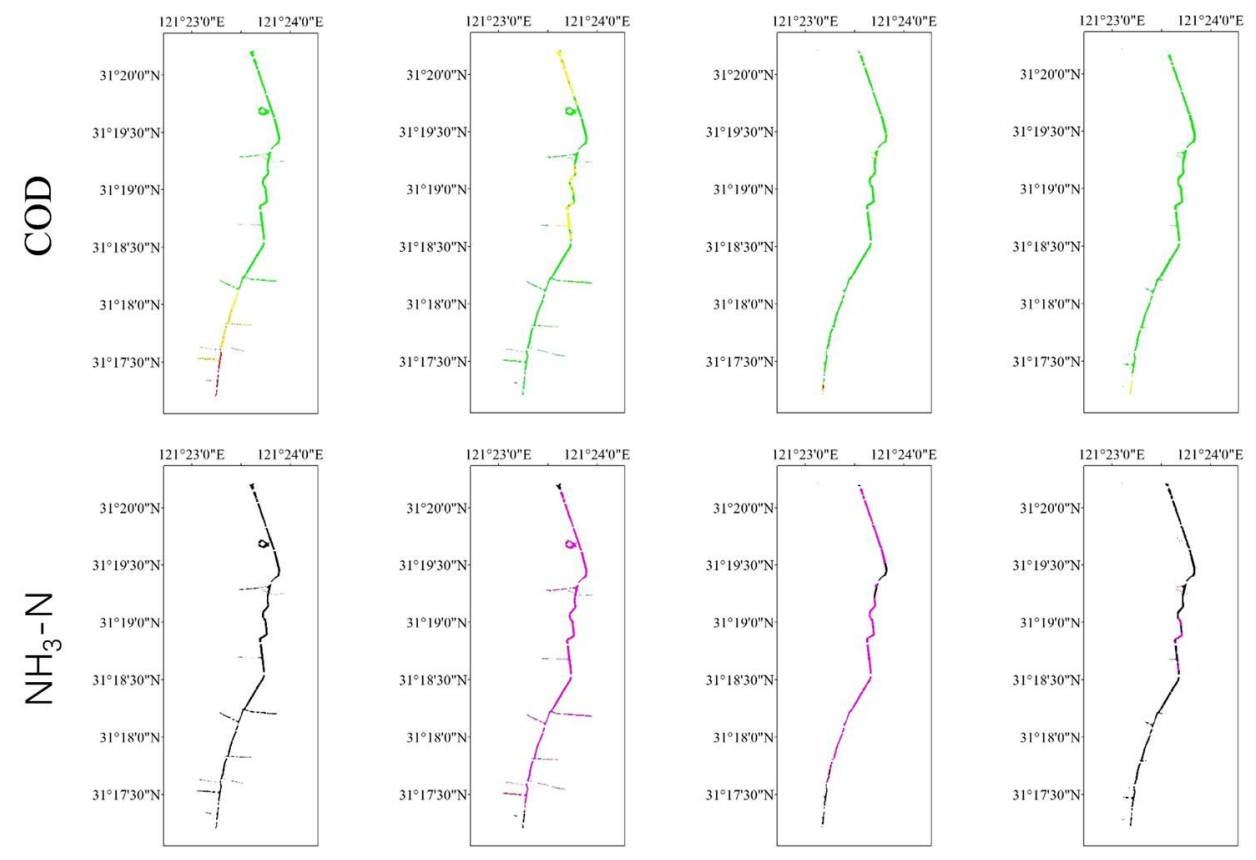

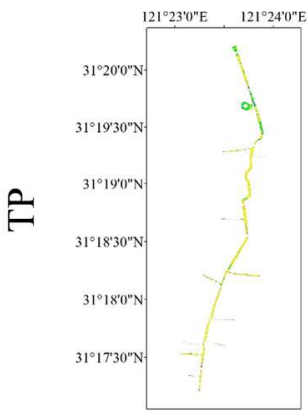

May 7

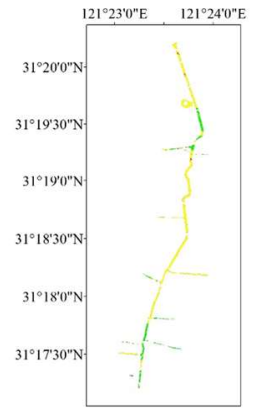

May 22

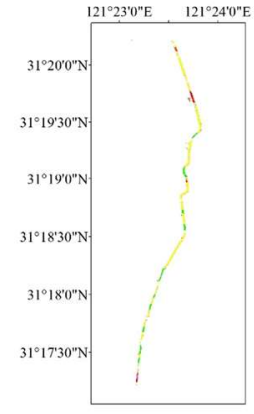

July 4

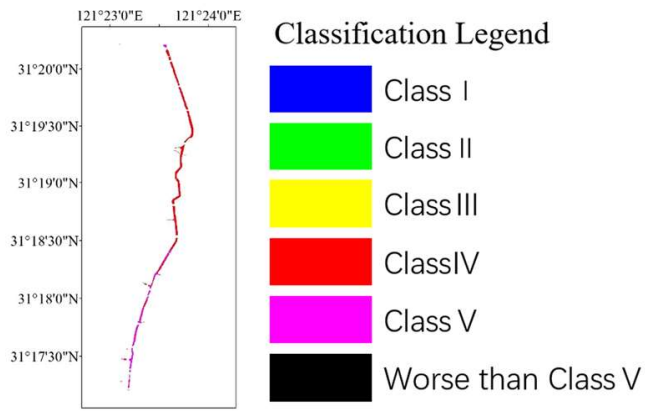

August 8

Figure 5. Multi-temporal water quality classification results of Taopu River

\section{REFERENCES}

Behmel, S., Damour, M., Ludwig, R., \& Rodriguez, M. J. 2016. Water quality monitoring strategies - A review and future perspectives. Science of The Total Environment, 571, 1312-1329.

Cabreira, T. M., Brisolara, L. B., \& Jr., P. R. F. 2019. Survey on Coverage Path Planning with Unmanned Aerial Vehicles. Drones, 3(1), 4.

Fargion, G. S., \& Mueller, J. L. 2000. Ocean optics protocols for satellite ocean color sensor vallidation. british journal of surgery, 47(201), 111-112.

Gholizadeh, M. H., Melesse, A. M., \& Reddi, L. 2016. A Comprehensive Review on Water Quality Parameters Estimation Using Remote Sensing Techniques. Sensors, 16(8), 1298.

Liu, Y., Zheng, Y., Liang, Y., Liu, S., \& Rosenblum, D. S. 2016. Urban water quality prediction based on multi-task multi-view learning. In IJCAI'16 Proceedings of the Twenty-Fifth International Joint Conference on Artificial Intelligence (pp. 2576-2582).
Lee, Z., Carder, K. L., Steward, R. G., Peacock, T. G., Davis, C. O., \& Mueller, J. L. 1997. Remote sensing reflectance and inherent optical properties of oceanic waters derived from abovewater measurements. In Proceedings of SPIE, the International Society for Optical Engineering (Vol. 2963, pp. 160-166).

Minarík, R., Langhammer, J., \& Hanus, J. 2019. Radiometric and Atmospheric Corrections of Multispectral $\mu \mathrm{MCA}$ Camera for UAV Spectroscopy. Remote Sensing, 11(20), 2428.

Nocerino, E., Dubbini, M., Menna, F., Remondino, F., Gattelli, M., \& Covi, D. 2017. Geometric calibration and radiometric correction of the maia multispectral camera. ISPRS International Archives of the Photogrammetry, Remote Sensing and Spatial Information Sciences, 149-156.

Ruddick, K. G., Cauwer, V. D., Park, Y.-J., \& Moore, G. 2006. Seaborne measurements of near infrared water - leaving reflectance. The similarity spectrum for turbid waters. Limnology and Oceanography, 51(2), 1167-1179.

Stöcker, C., Bennett, R., Nex, F., Gerke, M., \& Zevenbergen, J. 2017. Review of the Current State of UAV Regulations. Remote Sensing, 9(5), 459. 
Vidon, P., Tedesco, L. P., Pascual, D. L., Campbell, M. A., Casey, L. R., Wilson, J., \& Gray, M. 2008. Seasonal changes in stream water quality along an agricultural/urban land-use gradient. Proceedings of the Indiana Academy of Science, 117(2), 107-123.
Wang, M. 2006. Effects of ocean surface reflectance variation with solar elevation on normalized water-leaving radiance. Applied Optics, 45(17), 4122-4128.

Wang, X., \& Yang, W. 2019. Water quality monitoring and evaluation using remote sensing techniques in China: a systematic review. Ecosystem Health and Sustainability, 5(1), $47-56$. 